\title{
The Effect of Nozzle-to-plate Spacing on Unconfined Air-assistant Water Impinging Jets
}

\author{
Aspen W. Glaspell and Kyosung Choo \\ Mechanical and Industrial Engineering Department, Youngstown State University \\ Youngstown, $\mathrm{OH} 44555$, United States \\ kchoo@ysu.edu
}

\section{Extended Abstract}

Jet impingement is an attractive cooling mechanism due to the capability of achieving large heat transfer rates. This cooling method has been used in diverse industrial applications such as annealing of metals, tempering of glass, cooling of gas turbine blades, cooling in grinding processes and cooling of photovoltaic cells. Due to this diverse range of uses, many investigations have examined the heat transfer characteristics of jet impingement in the past decades. [1-4]. Recently, several researchers have examined heat transfer and fluid flow characteristics of single phase impinging jets at low nozzleto-plate spacings [5]. However, the effect of nozzle-to-plate spacing on heat transfer and fluid flow characteristics for unconfined air-assistant impinging jets is still limited.

The purpose of this study is to determine the influence of nozzle-to-plate spacing on heat transfer and fluid flow characteristics of unconfined air-assistant impinging jets. The working fluids are water and air. The influence of the nozzleto-plate spacings $(H / d=0.09-1.0)$ on the stagnation Nusselt number and pressure are considered. The stagnation pressure of the unconfined air-assistant impinging jets was measured to understand a relationship with heat transfer characteristics under a fixed water flow rate condition. An $x-y-z$ stage with a $10 \mu \mathrm{m}$ resolution controlled the nozzle-to-plate spacing (Thorlabs, Inc, PT3A/M). A mass flow controller (Omega FMA5520A) with an accuracy level of $\pm 1 \%$ and a repeatability of $\pm 0.15 \%$ controlled air flow rate. Water flow rate was controlled by a grear pump (Micropump). A heated surface was made by a stainless steel foil, which was connected with two copper bus-bars. A high voltage DC power supply (Agilent 6651A \#J03) supplied heat to the foil heater. Five K-type thermocouples of diameter $0.08 \mathrm{~mm}$ were used to measure the heater surface temperature using OMEGA (OM-CP-QuadTemp2000) digital data acquisition system.

The results show that stagnation pressure and the Nusselt number are divided into two regions; Region I) jet deflection region $(H / d \leq 0.45)$ and Region II) inertia dominant region $(0.45<H / d \leq 1.0)$. In region I, the Nusselt number drastically increases as the nozzle-to-plate spacing decreases due to the increase of the stagnation pressure by the jet deflection. In region II, the effect of the nozzle-to-plate spacing is negligible on the Nusselt number due to the inertia dominant effect.

\section{References}

[1] R. Chauhan, T. Singh, N. S. Thakur, N. Kumar, A. Kumar, "Heat transfer augmentation in solar thermal collectors using impinging air jets: A comprehensive review," Renewable and Sustainable Energy Reviews, https://doi.org/10.1016/j.rser.2017.10.025.

[2] S. G. Lee, M. Kaviany, C.-J. Kim, J. Lee, "Quasi-steady front in quench subcooled-jet impingement boiling: Experiment and analysis," International Journal of Heat and Mass Transfer, vol. 113, pp. 622-634, 2017.

[3] D. Trainer, "Breakup length and liquid splatter characteristics of air-assisted water jets," Int. J. Heat and Mass Transfer, vol. 81, pp. 77-87, 2016.

[4] R. Jenkins, R. Lupoi, R. Kempers, A. J. Robinson, "Heat transfer performance of boiling jet array impingement on micro-grooved surfaces," Experimental Thermal and Fluid Science, vol. 80, 293-304, 2017.

[5] K. Choo, B. K. Friedrich, A. W. Glaspell, K. A. Schilling, "The influence of nozzle-to-plate spacing on heat transfer and fluid flow of submerged jet impingement," Int. J. Heat and Mass Transfer, vol. 97, pp. 66-69, 2016.

[6] A. M. Kuraan, S. I. Moldovan, K. Choo, "Heat transfer and hydrodynamics of free water jet impingement at low nozzle-to-plate spacings," International Journal of Heat and Mass Transfer, vol. 108, pp. 2211-2216, 2017. 